\title{
Integrative Histologic and Bioinformatics Analysis of BIRC5/Survivin Expression in Oral Squamous Cell Carcinoma
}

\author{
Giuseppe Troiano ${ }^{1,+}+\mathbb{D}$, Agostino Guida ${ }^{2,+}$, Gabriella Aquino ${ }^{3}$, Gerardo Botti ${ }^{3}$, \\ Nunzia Simona Losito ${ }^{3}$, Silvana Papagerakis ${ }^{4}$, Maria Carmela Pedicillo ${ }^{1}$, Franco Ionna ${ }^{2}$, \\ Francesco Longo ${ }^{2}$, Monica Cantile ${ }^{3, *}$, Antonio Pennella ${ }^{1}$, Lucio Lo Russo ${ }^{1}$, Giovanni Di Gioia ${ }^{1}$, \\ Maria Addolorata Mariggiò ${ }^{5}$, Lorenzo Lo Muzio ${ }^{1}\left[{ }^{10}\right.$ and Giuseppe Pannone ${ }^{1}$ \\ 1 Department of Clinical and Experimental Medicine, University of Foggia, Via Rovelli 50, Foggia 71122, Italy; \\ giuseppe.troiano@unifg.it (G.T.); mariacarmela.pedicillo@unifg.it (M.C.P.); antonio.pennella@unifg.it (A.P.); \\ Lucio.lorusso@unifg.it (L.L.R.); digioia-giovanni@outlook.it (G.D.G.); lorenzo.lomuzio@unifg.it (L.L.M.); \\ giuseppe.pannone@unifg.it (G.P.) \\ 2 Maxillofacial and ENT Surgery Department, Istituto Nazionale per lo Studio e la Cura dei Tumori, \\ Fondazione G. Pascale, IRCCS, Naples 80131, Italy; agoguida@gmail.com (A.G.); \\ f.ionna@istitutotumori.na.it (F.I.); f.longo@istitutotumori.na.it (F.L.) \\ 3 Pathology Unit, Istituto Nazionale per lo Studio e la Cura dei Tumori, Fondazione G. Pascale, IRCCS, \\ Naples 80131, Italy; gabryaquino@gmail.com (G.A.); g.botti@istitutotumori.na.it (G.B.); \\ s.losito@istitutotumori.na.it (N.S.L.) \\ 4 Department of Surgery, Cancer Research Cluster, Room 4D10.2, Health Sciences Building, \\ Saskatchewan University, Saskatoon, SKS7N5E5, Canada; silvana.papagerakis@usask.ca \\ 5 Department of Biomedical Sciences and Human Oncology, University of Bari. Piazza Giulio Cesare 11, \\ Bari 70124, Italy; mariaaddolorata.mariggio@uniba.it (M.A.M.) \\ * Correspondence: m.cantile@istitutotumori.na.it; Tel.: +39-081-590-3744 \\ + These authors contributed equally to this work.
}

Received: 28 August 2018; Accepted: 2 September 2018; Published: 8 September 2018

\begin{abstract}
Survivin is a well-known protein involved in the inhibition of apoptosis in many different cancer types. The aim of this study was to perform an integrated bioinformatic and histologic analysis in order to study the expression and prognostic role of Survivin and its related gene BIRC5 in oral cancer. Publicly available databases were accessed via Gene Expression Omnibus and Oncomine, in addition raw data from The Cancer Genome Atlas (TCGA) were also obtained in order to analyze the rate of gene mutation, expression and methylation in patients with oral squamous cells carcinoma (OSCC). Immunohistochemistry (IHC) was also performed in order to evaluate the nuclear and cytoplasmic expression of Survivin and their correlation with cell proliferation in samples from OSCC patients. Results of this study revealed that Survivin is rarely mutated in OSCC samples and upregulated when compared to non-cancerous tissue. A negative correlation between the methylation of the island cg25986496 and BIRC5 mRNA expression was detected from TCGA data. IHC staining revealed that cytoplasmic (and not nuclear) expression of Survivin is associated with poor overall survival in OSCC patients, while the nuclear expression correlates with higher proliferation rate. In addition, data from TCGA database revealed that BIRC5 gene expression is an independent prognostic factor for OSCC patients.
\end{abstract}

Keywords: Survivin; BIRC5; immunohistochemistry; oral cancer; bioinformatic; TCGA 


\section{Introduction}

Over 500,000 new cases of head and neck squamous cell carcinoma (HNSCC) are reported annually worldwide [1]. Different subsites show various frequencies and environmental causes in world regions; in developed countries, approximately $75 \%$ of the oral cavity, larynx and pharynx cancers are attributable to tobacco smoking and alcohol consumption [2]. Oral squamous cell carcinoma (OSCC) is the most common subtype of HNSCC, accounting for more than 200,000 new cancer cases every year globally $[3,4]$. OSCC may appear in any location of oral cavity, although there are some anatomic subsites in which it is more commonly found: the anterior two-thirds of the tongue and the floor of the mouth [5-9]. Other subsites that may be involved are: buccal mucosa, retromolar area, gum, lip, soft palate and, less frequently, back of the tongue and hard palate. The etiology of OSCC is multifactorial; the most known risk factors are tobacco, excessive consumption of alcohol [10] and betel quid usage [11]: these factors can act separately or synergistically [12]. Other factors such as human papillomavirus (HPV) infection may also be involved [13], especially in the oro-pharynx. The overall five-year survival rate for OSCC is around 50-60\%, generally; such poor prognosis for OSCC is mostly accounted for by presentation at a late stage of the disease [14]. Some studies show that patients usually delay seeking professional advice on average for periods up to three months after having become aware of any oral symptom that could be linked to oral cancer [15]. Since cancer is still the second cause of death globally, after cardio-vascular disease, a lot of attention has been paid to its biomolecular mechanisms. Increasing evidence indicates that Survivin, a member of the inhibitor of apoptosis (IAP) protein family, is not only an essential protein molecule for apoptotic inhibition and regulation of mitosis, but it also plays a role in certain physiological processes, as well as in pathological conditions such as carcinogenesis in many human organs/cells [16,17].

It has been shown in various types of cancer that the transcriptional level of Survivin correlates with a more aggressive disease progression and poor clinical outcomes. In some types of cancers, the overexpression of Survivin may lead to overcoming the cell cycle checkpoints and thus, facilitate an aberrant progression of transformed cells through mitosis [18]. Survivin is usually overexpressed at G2/M phase, while its expression declines rapidly in G1 phase of the cell cycle. The baculoviral IAP repeat containing 5 (BIRC5) gene encoding human Survivin was cloned by Ambrosini et al. [19], it is $14.7 \mathrm{~kb}$ long, located near the telomeric end of chromosome 17 and encodes for the production of the wild-type Survivin protein [20]. Survivin is the smallest member of the IAP family and all its isoforms are characterized by containing only one of the characteristic N-terminal BIR (Baculovirus IAP Repeats) domains $[17,21]$. In order to help to organize, analyze, understand, visualize and store all information associated with biological macromolecules, the application of computational tools is becoming extremely helpful, giving birth to bioinformatics [22].

Bioinformatics has different aims: first, it allows researchers to organize data in an easier manner, to access them and add new entries as they are generated; the second purpose aims to develop tools and resources that help researchers in the process of data analysis; the third aim is to use these tools to cross reference data analysis and results interpretation in order to explain such findings from a biological point of view. Different types of data can be accessed via bioinformatics, including sequencing and expression results on a wide scale, allowing in this way to analyze results on a whole-genome and whole-exome level [23-27].

One of the advantages of performing bioinformatic analysis is the possibility to group together data on the basis of biological similarities accessing different sources of research [28]. Some large cancer projects, like The Cancer Genome Atlas (TCGA), have been performed, which aim to generate genomic and molecular profiling datasets and make them available to the scientific community for further analysis [29]. TCGA generated molecular profile data at the levels of gene expression, protein expression, DNA copy, DNA methylation, and somatic mutation [30]. The use of these databases allows users to perform integrated well-standardized analysis on various type of cancer, paving the way for studies aiming to integrate data from single institutions with that of multi-institutional databases [31]. 
The aim of this study was to perform an integrated bioinformatic and histologic analysis in order to study the expression of Survivin and its related gene BIRC5 in OSCC. The bioinformatics analysis focused on genetic mutations, mRNA expression, methylation and gene network. In addition, immunohistochemistry analysis from a single institution database was performed in order to study the prognostic significance of cytoplasmic and nuclear expression of Survivin in OSCC.

\section{Results}

\subsection{Bioinformatic Analyses}

Results of the comparative analysis between OSCC samples and non-cancer tissues revealed that the mRNA expression of BIRC5 was higher in the cancer samples compared both to leukoplakia samples and to normal tissue in healthy (non-cancerous) patients (Figure 1). The rate of BIRC5 mutations in 342 OSCC samples included in TCGA database revealed that only one $(0.29 \%)$ sample showed missense mutation, while mRNA upregulation was recorded in $14(4.09 \%)$ samples (Figure 2$)$. Data from in situ hybridization (ISH) revealed that five samples $(1.46 \%)$ were HPV positive. In addition, crossing data by primary subsite onset revealed that four out of five of these tumors were located at the base of the tongue, while for the remaining one the subsite of origin was unknown (Figure 2). Analysis of the network revealed that CDKN2a, MYC and FOXM1 control the expression of BIRC5, while AKT1-3, PRCACA, BUB1 and CSNK2A1 control a reaction that changes the state of the Survivin protein (Figure 3). Correlations analysis between BIRC5 mRNAs expression, methylation and clinicopathologic parameters of patients with OSCC revealed a statistically significant inverse correlation between the methylation of the island cg25986496 and the mRNA expression of BIRC5 $(\rho=-0.125)$, in addition mRNA expression correlated with the stage of the disease $(\rho=0.133)$ (Table 1). Cox-regression survival multivariate analysis revealed that BIRC 5 mRNA expression was an independent prognostic biomarker of overall survival ( $p$-value $=0.008)$ (Table 2$)$, while the methylation rate of the island cg25986496 showed $p$-values close to the significance $(p$-value $=0.068)$ for disease-free survival.
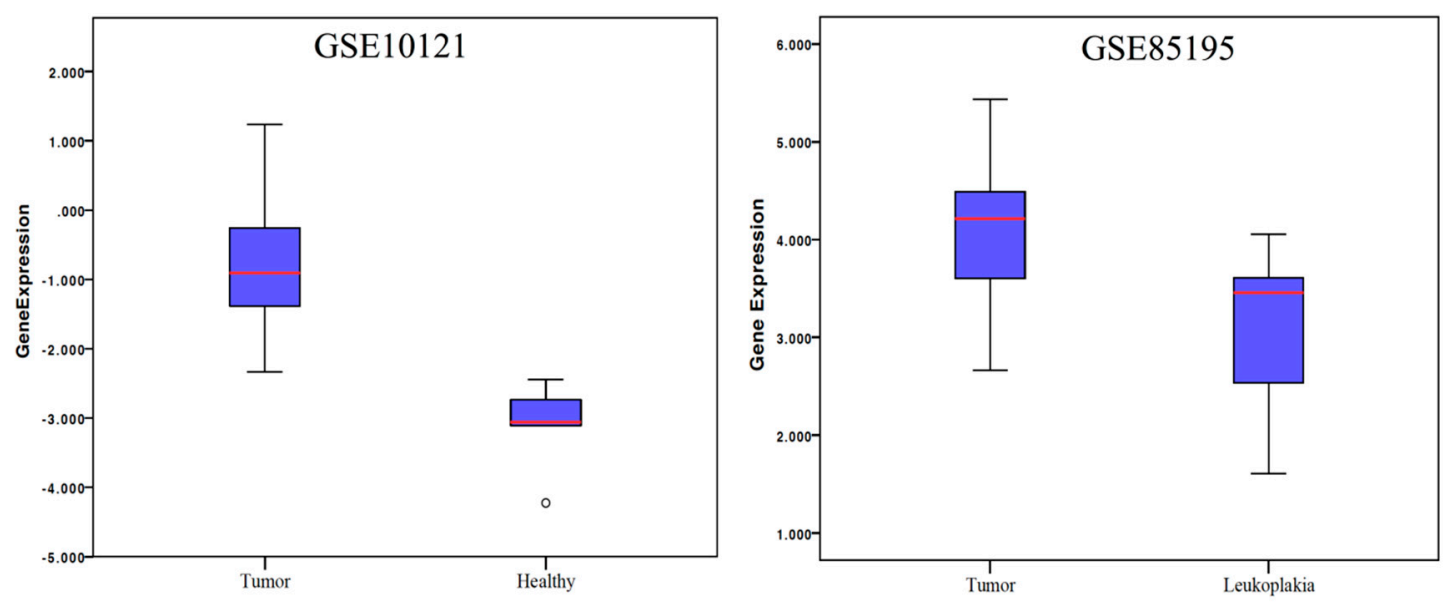

Figure 1. Analysis of previously published data comparing BIRC5 mRNA expression in cancer vs. non-cancer samples. 
Altered in 15 ( $4 \%$ ) of 342 sequenced cases/patients ( 342 total)

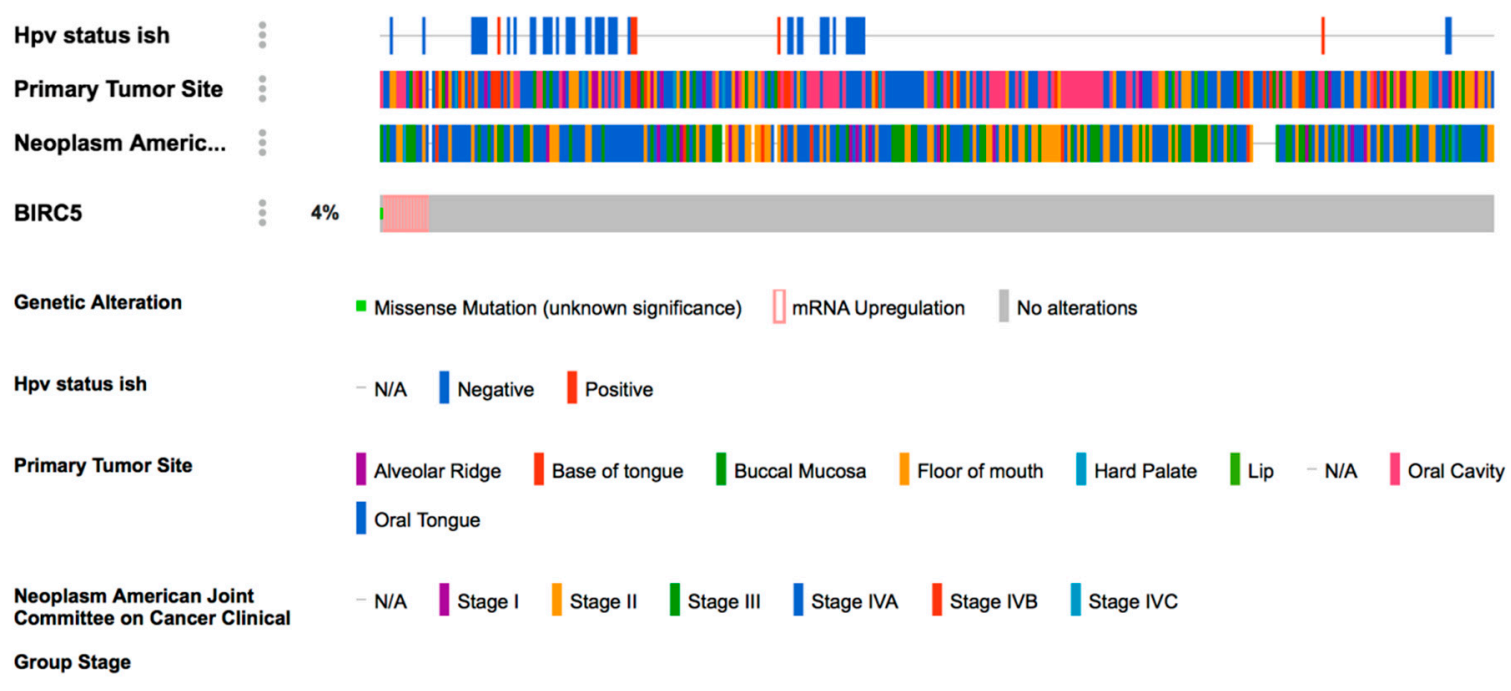

Figure 2. Analysis of OSCC patients included in the TCGA database by means of cBIOportal (http://www.cbioportal.org/) [32,33].

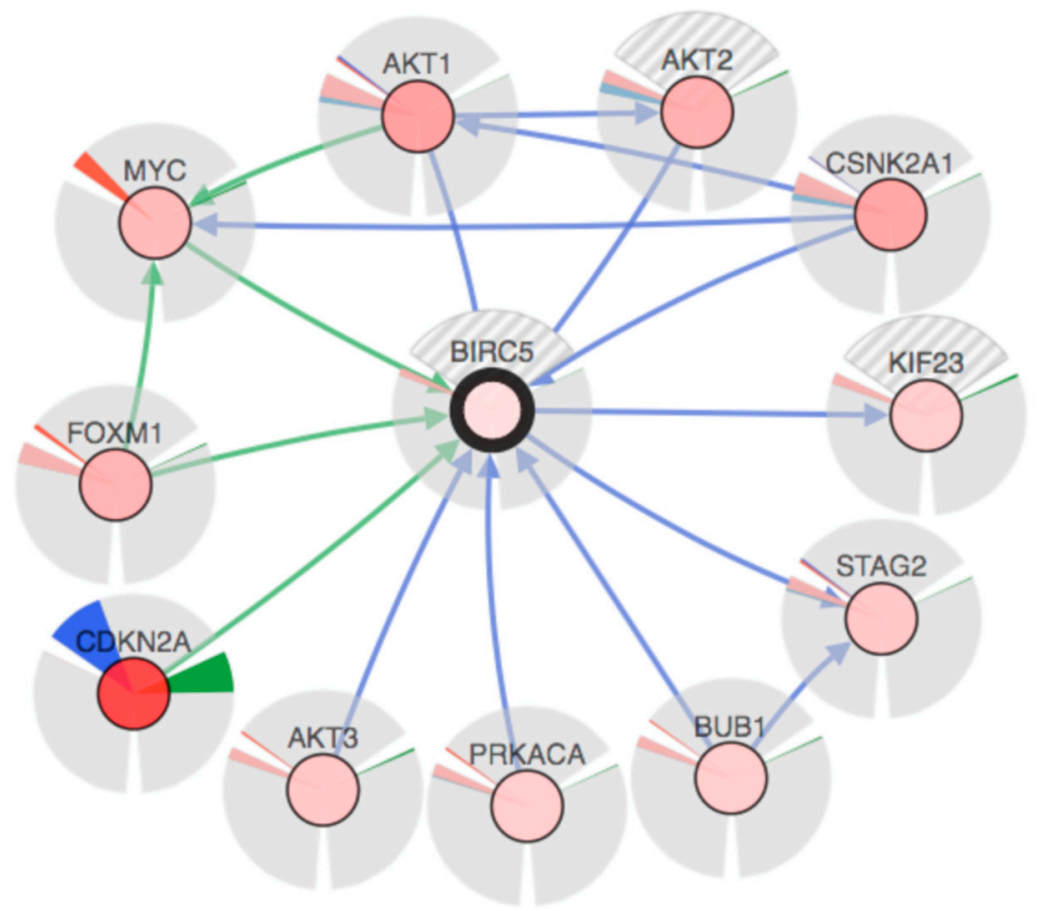

Figure 3. Network involved in the expression of the BIRC5 gene. Blue lines indicate genes controlling the state change of those genes to which the arrows are pointing; while the green lines indicate genes controlling the expression of those genes to which the arrows are pointing. Each gene is represented by a colored nucleus, indicating its overall alteration in the BIRC5 expression (the stronger the color intensity, the greater the alteration) surrounded by three areas: one filled with the color green, indicating how much the gene is mutated; the second one filled by both blue and red colors, indicating respectively the amount of homozygous deletion and the amplification of the gene; the third one filled by both pink and light blue colors, indicating respectively the upregulation and downregulation values of the gene. Where one or more areas are filled by grey and white stripes, data are missing. 
Table 1. Pearson's correlation of oral squamous cell carcinoma (OSCC) patients in the The Cancer Genome Atals (TCGA) database. Methylation rate refers to the island cg25986496, which was the probe with the strongest negative correlation to BIRC5 expression. * $p$-value lower than 0.05 .

\begin{tabular}{|c|c|c|c|c|c|}
\hline Variable & $\begin{array}{c}\text { mRNA } \\
\text { Expression }\end{array}$ & Methylation & Age & Stage & Grade \\
\hline mRNA expression & $\begin{array}{c}\rho=1 \\
p \text {-value }=1\end{array}$ & $\begin{array}{c}\rho=-0.125 \\
p \text {-value }=0.021 \text { * }\end{array}$ & $\begin{array}{c}\rho=0.025 \\
p \text {-value }=0.644\end{array}$ & $\begin{array}{c}\rho=0.137 \\
p \text {-value }=0.015 *\end{array}$ & $\begin{array}{c}\rho=0.023 \\
p \text {-value }=0.670\end{array}$ \\
\hline Methylation & & $\begin{array}{c}\rho=1 \\
p \text {-value }=1\end{array}$ & $\begin{array}{c}\rho=0.085 \\
p \text {-value }=0.119\end{array}$ & $\begin{array}{c}\rho=0.019 \\
p \text {-value }=0.735\end{array}$ & $\begin{array}{c}\rho=-0.099 \\
p \text {-value }=0.070\end{array}$ \\
\hline Age & & & $\begin{array}{c}\rho=1 \\
p \text {-value }=1\end{array}$ & $\begin{array}{c}\rho=-0.099 \\
p \text {-value }=0.083\end{array}$ & $\begin{array}{c}\rho=0.118 \\
p \text {-value }=0.033 *\end{array}$ \\
\hline Stage & & & & $\begin{array}{c}\rho=1 \\
p \text {-value }=1\end{array}$ & $\begin{array}{c}\rho=-0.094 \\
p \text {-value }=0.104\end{array}$ \\
\hline Grade & & & & & $\begin{array}{c}\rho=1 \\
p \text {-value }=1\end{array}$ \\
\hline
\end{tabular}

Table 2. Cox regression analysis of patients included in the TCGA database. * $p$-value lower than 0.05 .

\begin{tabular}{ccccc}
\hline \multirow{2}{*}{ Variable } & \multicolumn{2}{c}{ Overall Survival } & \multicolumn{2}{c}{ Disease Free Survival } \\
\cline { 2 - 5 } & Hazard Ratio & $\boldsymbol{p}$-Value & Hazard Ratio & $\boldsymbol{p}$-Value \\
\hline mRNA expression & 1.182 & $0.008^{*}$ & 0.906 & 0.653 \\
Methylation rate & 2.350 & 0.577 & 0.004 & 0.068 \\
Grade & 0.779 & 0.209 & 0.799 & 0.657 \\
Stage & 0.965 & 0.637 & 1.806 & $0.021^{*}$ \\
Age & 0.996 & 0.474 & 1.007 & 0.694 \\
Gender & 0.997 & 0.988 & 0.574 & 0.259 \\
\hline
\end{tabular}

\subsection{Tissue Micro Array (TMA) Immunohistochemistry (IHC) Analysis}

Cytoplasmic and nuclear staining of Survivin were performed through IHC analysis on a TMA comprising 107 samples of OSCC patients admitted to the National Cancer Institute "Giovanni Pascale" between 1997 and 2008. The clinical and pathological information of patients included in the TMA have been summarized in Table 3. The immunostaining findings were expressed as a percentage of positivity of the cytoplasmic or nuclear staining of Survivin-positive cells. A threshold of $60 \%$ of positivity was chosen to subcategorize patients relative to low/high expression of Survivin. Pearson analysis revealed a direct correlation between the cytoplasmic and nuclear expression of Survivin $(\rho=0.319)$. In addition, a direct correlation with the histological grade of the tumor was also recorded for both nuclear $(\rho=0.215)$ and cytoplasmic $(\rho=0.218)$ expression. Both Kaplan-Meier (univariate) and Cox regression (multivariate) analysis revealed that only the cytoplasmic expression of Survivin was an independent prognostic factor of overall survival in OSCC (Figure 4 and Table 4).

Table 3. Clinicopathologic features of the OSCC patients in the authors' institutional database.

\begin{tabular}{ccc}
\hline ClinicoPathological Parameter & Groups & Number \\
\hline \multirow{2}{*}{ Age } & $\geq 65$ years old & $63 / 107(58.9 \%)$ \\
& $<65$ years old & $44 / 107(41.1 \%)$ \\
Gender & Male & $76 / 107(71 \%)$ \\
& Female & $31 / 107(29 \%)$ \\
Grade & G1 & $21 / 107(19.6 \%)$ \\
& G2/G3 & $86 / 107(90.4 \%)$ \\
Stage & St1/St2 & $39 / 107(36.4 \%)$ \\
& St3/St4 & $68 / 107(63.6 \%)$ \\
Subsite Involved & Tongue & $64 / 107(59.8 \%)$ \\
& Others sites & $43 / 107(40.2 \%)$ \\
\hline
\end{tabular}




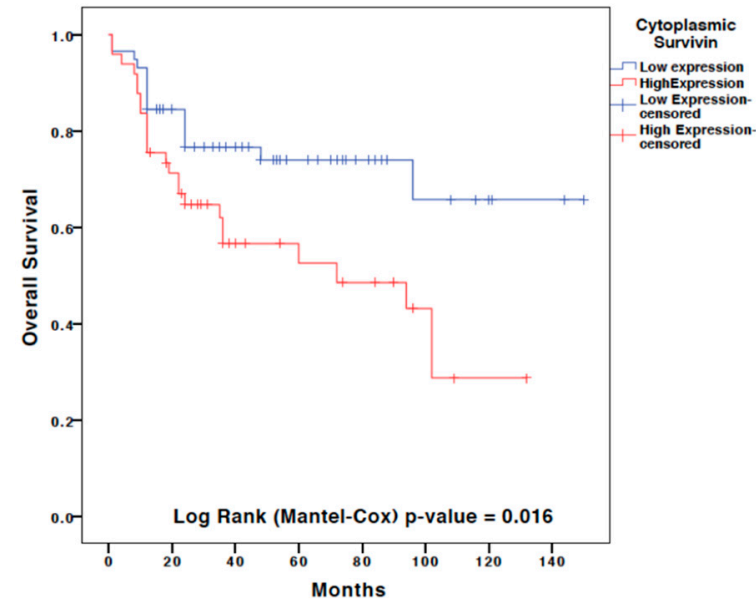

(A)

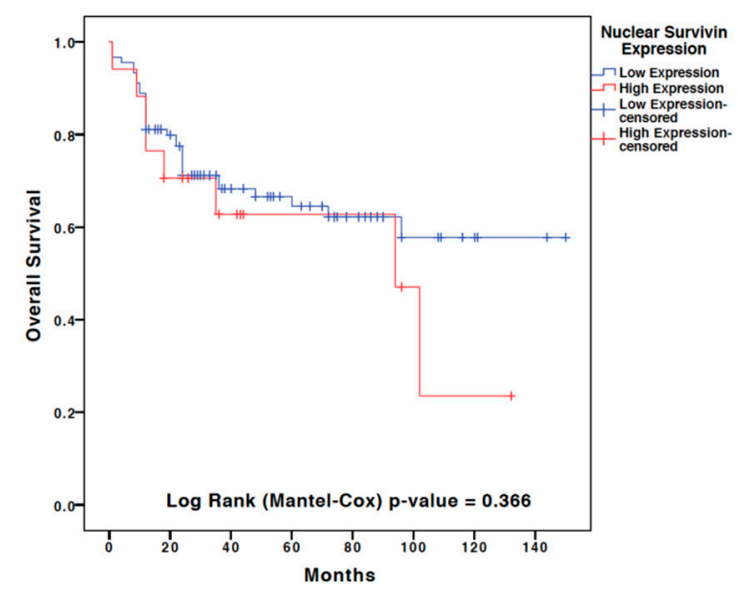

(B)

Figure 4. Kaplan-Meier curves of overall survival for the immunohistochemical expression of (A) cytoplasmic or (B) nuclear cellular localization of Survivin in the authors' own database.

Table 4. Multivariate analysis of cytoplasmic and nuclear expression of Survivin as indicator of poor overall survival in the OSCC patients included in this study (authors' institutional database) (Note: * indicates statistically significance with $p<0.05$ ).

\begin{tabular}{ccc}
\hline \multirow{2}{*}{ Clinicopathologic Factor } & \multicolumn{2}{c}{ Overall Survival } \\
\cline { 2 - 3 } & Hazard Ratio & $p$-Value \\
\hline Cytoplasmic Survivin & 2.040 & $0.045^{*}$ \\
Nuclear Survivin & 0.858 & 0.726 \\
Grade & 1.961 & 0.220 \\
Stage & 4.938 & $0.001^{*}$ \\
Age & 0.895 & 0.734 \\
Gender & 0.781 & 0.490 \\
\hline
\end{tabular}

IHC of leukoplakia ( $N=10$ cases) and normal mucosa ( $N=12$ cases) samples from healthy (non-cancerous patients) revealed that Survivin expression was almost exclusively nuclear and confined to the basal third of the epithelium (Supplementary Materials). Particulary, the average percentage of Survivin expression was $8.3 \%$ in the leukoplakia samples, versus $0.54 \%$ in the normal mucosa.

\section{Discussion}

Survivin is a well-known protein that belongs to the family of the inhibitor of apoptosis proteins (IAP) family. It is encoded by the BIRC5 gene located on the chromosome 17q25 [19].To our knowledge, only one meta-analysis has been previously published by pooling data from various studies evaluating the significance of Survivin (at either mRNA or protein levels) as a prognostic factor in OSCC patients. Results of such meta-analysis were controversial encouraging the development of further cohort studies on the topic [34]. In this current study, we decided to perform an integrated analysis of BIRC5/Survivin expression using both IHC analysis on authors' institutional databases and a bioinformatics analysis on publicly available databases. Although a direct comparison between these two databases (GSE10121 and GSE85195) was not possible, our comparative analysis indicated that the BIRC5 mRNA was upregulated in OSCC compared both to leukoplakia and oral normal tissue (Figure 1). In addition, the presence/absence of mutations of the BIRC5 gene was analyzed revealing that this gene is very rarely mutated in OSCC. Furthermore, already published databases were accessed through Oncomine and GEO2 $r$ in order to compare the expression of BIRC5 mRNA in OSCC, precancerous tissue and normal tissue from healthy non-cancerous patients. The bioinformatic analysis also allowed us to evaluate a 
novel direction relevant to the OSCC topic, that is the low frequency of HPV-positive OSCC tumors with respect to other sites in the head and neck area. The results obtained from the analysis of the TCGA database are in agreement with previous studies from other cohorts, which revealed a low rate of HPV positive tumors in the oral cavity, located particularly at the base of the tongue [35-38]. One of the main challenges in the OSCC study through online tools is that TCGA database includes cases from the whole head and neck area, which makes it difficult to perform subgroup analysis targeting only the OSCC patients. For such reasons, we decided to access the raw data from the TCGA database and manually select cases by the primary tumor anatomical site, which allowed us to identify 342 OSCC patients which we included in this current analysis.

We then analyzed this cohort composed of these 342 OSCC patients and their respective available data of mRNA expression and methylation rate through cBIOportal. The multivariate analysis of this data revealed that BIRC5 mRNA expression is an independent prognostic factor in OSCC and correlates with tumor stage. These findings are in accordance with what was previously reported in the literature $[39,40]$. In addition, we found a group of genes that seem to be highly involved in BIRC5 expression: AKT1, AKT2, AKT3, BUB1, CDKN2A, CSKN2A1, FOXM1, KIF23, MYC, PRKACA, STAG2. In Figure 3 it can be noticed that the mostly altered gene is $C D K N 2 A$, which is also showing the highest levels of mutation and homozygous deletion. Only CDKN2A, MYC and FOXM1 are responsible for the control of the BIRC5 expression, while the remaining genes control the genetic alterations of BIRC5. It is critical to note that $A K T 1$ and FOXM1 also control the expression of $M Y C$, while CSNK2A1 controls its state of change (i.e. genetic alterations). CSNK2A1 also controls the genetic alterations of both $M Y C$ and $A K T 1$, which in turns control the state of change of $A K T 2$. A statistically significant inverse correlation was found between the methylation rate reported on cBioPortal and BIRC5 mRNA expression $(\rho=-0.125)$. It is important to highlight only methylation data from the probe with the strongest negative correlation between the methylation signal and the respective gene expression were included in the cBioPortal data for genes with multiple probes. Hence, we decided to download all the raw data from the TCGA database in order to find out which was the probe involved in the correlation with BIRC5 expression. By matching data between cBioPortal and TCGA, we found that the correlation was related to the island cg25986496. The possibility that the gene expression may be regulated by an epigenetic mechanism has already been reported [41]. Further functional studies on cell lines are needed to confirm this association between the methylation of the island cg25986496 and BIRC5 mRNA expression.

To address the discordance among various studies regarding prognostic value of the Survivin, we extended our analysis and assessed its intracellular distribution [34,42-44]. Thus, we evaluated the Survivin cytoplasmic and nuclear localization in a TMA composed of 107 OSCC cases; in addition, 12 cases of leukoplakia and 10 cases of normal mucosa samples from healthy (non-cancerous) patients were comparatively analyzed. The Survivin "cytoplasmic" or "nuclear" IHC staining extend was subsequently scored as high versus low in the analyzed sample, based on a $60 \%$ cut-off score of positivity; no difference was noted in the intensity of the Survivin expression, thus the staining intensity was not scored (Figure 5). Our IHC analysis has shown that Survivin was only weakly expressed in the basal third of oral mucosa in both leukoplakia and normal oral mucosa samples. Furthermore, in contrast to what was previously reported [42], Survivin was found predominantly expressed in the nuclei, while a weak cytoplasmic expression was only noted in one case of leukoplakia. Staining for Ki67 was also performed in the same TMA in order to investigate the correlation of the subcellular localization with cells proliferation. This analysis revealed that the nuclear localization of Survivin was correlated with a higher cell proliferation (quantified as percentage of Ki-67 expression). These findings are in alignment with other previously published studies, which reported that patients with higher nuclear expression of Survivin had a better response to radiotherapy [45]. Furthermore, our study found that both the cytoplasmic and nuclear expression of Survivin correlated with tumor grade, while no correlation with the tumor stage was detected. In order to study whether the subcellular location of Survivin correlated with OSCC prognosis, we performed a multivariate analysis taking into 
account the OSCC tumor stage, grade, patient sex and age and the Survivin cytoplasmic or nuclear expression levels. Results of this analysis revealed that the cytoplasmic localization of Survivin (HR $=2.040)$ and the tumor stage $(H R=4.938)$ were independent prognostic factors in OSCC. Results of this TMA analysis revealed that the cytoplasmic localization of Survivin $(H R=2.040)$ and the tumor stage $(H R=4.938)$ were independent prognostic factors in OSCC. These data are in disagreement with other papers $[42,43,46]$, and in accordance with what was originally reported by our group in a series of OSCCs using whole section specimens [21]. The discordance with previously published studies could be due to the sensitivity of the different methods of detection that were employed, a more homogeneous and larger cohort of cases (the TMA included 107 pathologists-selected OSCC positive core-biopsies, in their vast majority with higher histological grade and advanced tumor stage), and most importantly that in this study we performed a multivariate analysis adjusting for well-known covariates. Overall, our results are in accordance with previous studies, which indicate that the Survivin cytoplasmic expression is correlated with increased tumor aggressiveness and a lower positive response to radiotherapy treatment in OSCC patients [47-50].

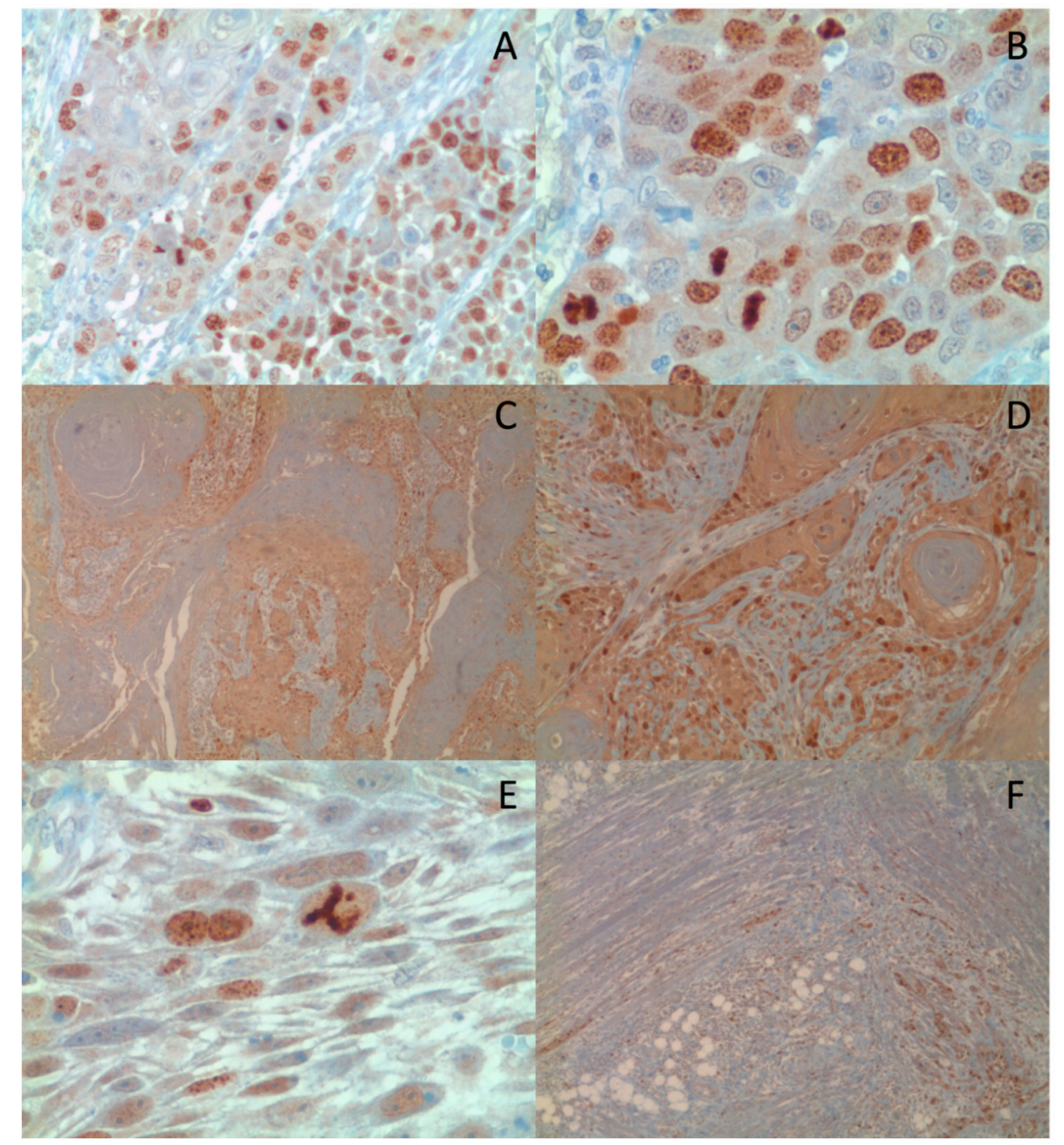

Figure 5. Nuclear (A 10x, B 20x) and Cytoplasmic (C 4x, D 10x) expression of Survivin by IHC. Survivin was also expressed in cases showing aberrant mitosis (E 40x) and muscular invasion (F 4x). 
In conclusion, it is imperative that the subcellular analysis of Survivin expression will be further evaluated through additional well-standardized cohort studies, adjusted for other prognostic covariates, in order to better clarify its role in the prognosis prediction of OSCC patients.

\section{Materials and Methods}

\subsection{Patients Database}

All OSCC patients from the authors institutional database had been treated, not consequentially, at the Istituto Nazionale Tumori "IRCCS_Fondazione G. Pascale", Naples, Italy, with therapeutic intent for their cancer, according to National Comprehensive Cancer Network (NCCN) guidelines, not undergoing experimental procedures. Informed consent was obtained from all patients, after careful explanations, authorizing re-examination of specimens of biological samples for research purposes, as approved by our Institute in the Resolution of the Extraordinary Commissioner; number: 15, date: 15 January 2016, establishing and regulating our Biobank.

\subsection{Comparison of BIRC5 Gene Expression between Tumor vs. Non-Tumor Samples}

The expression level of the BIRC5 mRNA in OSCC samples compared to normal tissue was analyzed through Oncomine gene expression array datasets (https://www.oncomine.org/). In addition, the gene expression profiles of two published databases (GSE85195 and GSE10121) were downloaded from Gene Expression Omnibus (GEO) using the GEO2R platform (https: / / www.ncbi. nlm.nih.gov/geo/geo2r/). In the GSE85195 database, data for gene expression profiling of Oral Leukoplakia (OL) and Early Stage OSCC were available [51], while in GSE10121 a comparison between primary OSCCs and oral mucosa from healthy,non-cancerous patients was performed [52].

\subsection{Analysis of BIRC5 Mutations, Methylation and Associated Network in OSCC from The Cancer Genome Atlas (TCGA) Database}

Clinical data from TCGA database for patients with HNSCC were downloaded using the software TCGA2BED [53]. The data were catalogued in Microsoft Excel and manually checked on the basis of the primary site of tumor onset in order to exclude non-OSCC patients. Hence, the ID of OSCC patients in TCGA were manually entered in the cBioPortal for Cancer Genomics (http:/ /www.cbioportal.org) in order to analyze the presence of mutations and investigate the associated network of BIRC5. Data for TCGA methylation derived from Human Methylation-450 Bead Chip assay and data of BIRC5 mRNA expression obtained by RNA-sequencing V2 RSEM (Illumina RNA Sequencing version 2) were also downloaded from cBioPortal. To note, for genes with multiple CpG-Islands, as BIRC5, only methylation data from the probe with the strongest negative correlation between the methylation signal and the gene expression were available (http:/ / www.cbioportal.org/) [32,33]. All the raw data obtained from TCGA and GEO databases were entered in SPSS 21.0 in order to perform statistical analyses of correlation with outcome and survival among different groups.

\subsection{Analysis of Survivin Expression in a Tissue Micro Array of OSCC, Leukoplakia and Healthy Mucosa Samples}

All patients had provided written informed consent for the analysis of samples according to the institutional regulations and the study was approved by the ethics committee of the National Cancer Institute "Giovanni Pascale" and the resulting biobank collection of the analyzed specimens was registered as "Bio-Banca Istituzionale BBI" Deliberation (Number: 15, Date: 15 January 2016). For the analysis of Survivin expression, a tissue microarray (TMA) including pathologists-selected tumor core-biopsies from 107 OSCC cases; these cases were part of a larger TMA of 120 cases OSCC our group previously published [54]. The source paraffin blocks were cored and $0.6 \mathrm{~mm}$ cores (area: $0.28 \mathrm{~mm}^{2}$ ) transferred to the recipient master block using Galileo TMA CK 3500 Tissue Microarrayer (ISE TMA Software, Integrated System Engineering, Milan, Italy). Four cores from different areas of the same 
tissue block were arrayed for each case. All the donor cores were formatted into one recipient block. Hematoxylin and eosin (H\&E) staining of a $4-\mu \mathrm{m}$ of the analysed TMA was used to verify the integrity of all samples. In addition, 12 cases of leukoplakia and 10 cases of normal oral mucosa samples from healthy non-cancerous patients were enrolled as negative controls. Expression of Survivin was identified using a rabbit polyclonal antibody supplied by NOVUS (catalog number NB500-201 NOVUS Biologicals, Littleton, CO, USA) raised against full-length recombinant Survivin; the KI-67 rabbit monoclonal antibody supplied by Roche (Ventana-Roche, Monza, Italy) was used to assess the cell proliferation. Primary Abs were revealed by automated staining device (Ventana Benchmark) using standard linked strepatavidin-biotin horseradish peroxidase technique (LSAB-HRP). Immune-stained cells were detected in 4 high-power fields (HPFs) under an optical microscope (OLYMPUS BX53, at x200). Immune-stained spots were acquired by digital camera and analyzed by ISE TMA Software (Integrated System Engineering), and Cellsens V1.9 ${ }^{\circledR}$ Olympus image analysis software.

Supplementary Materials: The following are available online at http:/ /www.mdpi.com/1422-0067/19/9/2664/ s1.

Author Contributions: G.T., A.G., G.A., M.C. and G.P. were responsible for the conception and design of the study. F.L., F.I. were responsible for provision of patients' clinical information. M.C.P., G.A., A.P., M.A.M. and L.L.R. collected samples for immunohistochemical analysis. N.S.L., G.P., S.P. and G.B. were responsible for immunohistochemical evaluation. G.D.G., L.L.M. and G.T. were responsible for statistical and bioinformatic analysis. G.P., M.C., A.G. and G.T. were responsible for paper elaboration and revision. All authors were involved in manuscript writing and provided final approval of the manuscript.

Funding: This study was supported by the Italian Ministry of Health and bio-materials (Tissues and blood) for in vivo studies were provided by Institutional BioBank (BBI) of INT Fondazione Pascale.

Conflicts of Interest: The authors declare no conflict of interest.

\section{References}

1. Torre, L.A.; Bray, F.; Siegel, R.L.; Ferlay, J.; Lortet-Tieulent, J.; Jemal, A. Global cancer statistics, 2012. CA Cancer J. Clin. 2015, 65, 87-108. [CrossRef] [PubMed]

2. Tuyns, A.J.; Esteve, J.; Raymond, L.; Berrino, F.; Benhamou, E.; Blanchet, F.; Boffetta, P.; Crosignani, P.; del Moral, A.; Lehmann, W.; et al. Cancer of the larynx/hypopharynx, tobacco and alcohol: IARC international case-control study in Turin and Varese (Italy), Zaragoza and Navarra (Spain), Geneva (Switzerland) and Calvados (France). Int. J. Cancer 1988, 41, 483-491. [CrossRef] [PubMed]

3. Massano, J.; Regateiro, F.S.; Januario, G.; Ferreira, A. Oral squamous cell carcinoma: Review of prognostic and predictive factors. Oral Surg. Oral Med. Oral Pathol. Oral Radiol. Endodontol. 2006, 102, 67-76. [CrossRef] [PubMed]

4. Thomson, P.J. Perspectives on oral squamous cell carcinoma prevention-proliferation, position, progression and prediction. J. Oral Pathol. Med. 2018. [CrossRef] [PubMed]

5. Hirata, R.M.; Jaques, D.A.; Chambers, R.G.; Tuttle, J.R.; Mahoney, W.D. Carcinoma of the oral cavity. An analysis of 478 cases. Ann. Surg. 1975, 182, 98-103. [CrossRef] [PubMed]

6. Oliver, A.J.; Helfrick, J.F.; Gard, D. Primary oral squamous cell carcinoma: A review of 92 cases. J. Oral Maxillofac. Surg. 1996, 54, 949-954. [CrossRef]

7. Mashberg, A.; Merletti, F.; Boffetta, P.; Gandolfo, S.; Ozzello, F.; Fracchia, F.; Terracini, B. Appearance, site of occurrence, and physical and clinical characteristics of oral carcinoma in Torino, Italy. Cancer 1989, 63, 2522-2527. [CrossRef]

8. Jovanovic, A.; Schulten, E.A.; Kostense, P.J.; Snow, G.B.; van der Waal, I. Tobacco and alcohol related to the anatomical site of oral squamous cell carcinoma. J. Oral Pathol. Med. 1993, 22, 459-462. [CrossRef] [PubMed]

9. Brandizzi, D.; Gandolfo, M.; Velazco, M.L.; Cabrini, R.L.; Lanfranchi, H.E. Clinical features and evolution of oral cancer: A study of 274 cases in Buenos Aires, Argentina. Med. Oral Patol. Oral Cir. Bucal. 2008, 13, E544-E548. [PubMed]

10. Hindle, I.; Downer, M.C.; Moles, D.R.; Speight, P.M. Is alcohol responsible for more intra-oral cancer? Oral Oncol. 2000, 36, 328-333. [CrossRef]

11. Warnakulasuriya, S. Living with oral cancer: Epidemiology with particular reference to prevalence and life-style changes that influence survival. Oral Oncol. 2010, 46, 407-410. [CrossRef] [PubMed] 
12. Blot, W.J.; McLaughlin, J.K.; Winn, D.M.; Austin, D.F.; Greenberg, R.S.; Preston-Martin, S.; Bernstein, L.; Schoenberg, J.B.; Stemhagen, A.; Fraumeni, J.F., Jr. Smoking and drinking in relation to oral and pharyngeal cancer. Cancer Res. 1988, 48, 3282-3287. [PubMed]

13. Herrero, R.; Castellsague, X.; Pawlita, M.; Lissowska, J.; Kee, F.; Balaram, P.; Rajkumar, T.; Sridhar, H.; Rose, B.; Pintos, J.; et al. Human papillomavirus and oral cancer: The International Agency for Research on Cancer multicenter study. J. Natl. Cancer Inst. 2003, 95, 1772-1783. [CrossRef] [PubMed]

14. Rogers, S.N.; Brown, J.S.; Woolgar, J.A.; Lowe, D.; Magennis, P.; Shaw, R.J.; Sutton, D.; Errington, D.; Vaughan, D. Survival following primary surgery for oral cancer. Oral Oncol. 2009, 45, 201-211. [CrossRef] [PubMed]

15. Gomez, I.; Warnakulasuriya, S.; Varela-Centelles, P.I.; Lopez-Jornet, P.; Suarez-Cunqueiro, M.; Diz-Dios, P.; Seoane, J. Is early diagnosis of oral cancer a feasible objective? Who is to blame for diagnostic delay? Oral Dis. 2010, 16, 333-342. [CrossRef] [PubMed]

16. Jaiswal, P.K.; Goel, A.; Mittal, R.D. Survivin: A molecular biomarker in cancer. Indian J. Med. Res. 2015, 141, 389-397. [PubMed]

17. Altieri, D.C. Survivin, versatile modulation of cell division and apoptosis in cancer. Oncogene 2003, 22, 8581-8589. [CrossRef] [PubMed]

18. Sah, N.K.; Khan, Z.; Khan, G.J.; Bisen, P.S. Structural, functional and therapeutic biology of survivin. Cancer Lett. 2006, 244, 164-171. [CrossRef] [PubMed]

19. Ambrosini, G.; Adida, C.; Altieri, D.C. A novel anti-apoptosis gene, survivin, expressed in cancer and lymphoma. Nat. Med. 1997, 3, 917-921. [CrossRef] [PubMed]

20. Wheatley, S.P.; McNeish, I.A. Survivin: A protein with dual roles in mitosis and apoptosis. Int. Rev. Cytol. 2005, 247, 35-88. [CrossRef]

21. Lo Muzio, L.; Pannone, G.; Staibano, S.; Mignogna, M.D.; Rubini, C.; Mariggio, M.A.; Procaccini, M.; Ferrari, F.; de Rosa, G.; Altieri, D.C. Survivin expression in oral squamous cell carcinoma. Br. J. Cancer 2003, 89, 2244-2248. [CrossRef] [PubMed]

22. Luscombe, N.M.; Greenbaum, D.; Gerstein, M. What is bioinformatics? A proposed definition and overview of the field. Methods Inf. Med. 2001, 40, 346-358. [CrossRef] [PubMed]

23. Eisen, M.B.; Brown, P.O. DNA arrays for analysis of gene expression. Methods Enzymol. 1999, 303, $179-205$. [PubMed]

24. Cheung, V.G.; Morley, M.; Aguilar, F.; Massimi, A.; Kucherlapati, R.; Childs, G. Making and reading microarrays. Nat. Genet. 1999, 21, 15-19. [CrossRef] [PubMed]

25. Duggan, D.J.; Bittner, M.; Chen, Y.; Meltzer, P.; Trent, J.M. Expression profiling using cDNA microarrays. Nat. Genet. 1999, 21, 10-14. [CrossRef] [PubMed]

26. Lipshutz, R.J.; Fodor, S.P.; Gingeras, T.R.; Lockhart, D.J. High density synthetic oligonucleotide arrays. Nat. Genet. 1999, 21, 20-24. [CrossRef] [PubMed]

27. Velculescu, V.E.; Zhang, L.; Vogelstein, B.; Kinzler, K.W. Serial analysis of gene expression. Science 1995, 270, 484-487. [CrossRef] [PubMed]

28. Gerstein, M. Integrative database analysis in structural genomics. Nat. Struct. Mol. Biol. 2000, 7, 960-963. [CrossRef] [PubMed]

29. Wong, N.; Khwaja, S.S.; Baker, C.M.; Gay, H.A.; Thorstad, W.L.; Daly, M.D.; Lewis, J.S., Jr.; Wang, X. Prognostic microRNA signatures derived from The Cancer Genome Atlas for head and neck squamous cell carcinomas. Cancer Med. 2016, 5, 1619-1628. [CrossRef] [PubMed]

30. Wang, Z.; Jensen, M.A.; Zenklusen, J.C. A Practical Guide to The Cancer Genome Atlas (TCGA). Methods Mol. Biol. 2016, 1418, 111-141. [PubMed]

31. Creighton, C.J. Making Use of Cancer Genomic Databases. Curr. Protoc. Mol. Biol. 2018, 121. [CrossRef]

32. Cerami, E.; Gao, J.; Dogrusoz, U.; Gross, B.E.; Sumer, S.O.; Aksoy, B.A.; Jacobsen, A.; Byrne, C.J.; Heuer, M.L.; Larsson, E.; et al. The cBio cancer genomics portal: An open platform for exploring multidimensional cancer genomics data. Cancer Discov. 2012, 2, 401-404. [CrossRef] [PubMed]

33. Gao, J.; Aksoy, B.A.; Dogrusoz, U.; Dresdner, G.; Gross, B.; Sumer, S.O.; Sun, Y.; Jacobsen, A.; Sinha, R.; Larsson, E.; et al. Integrative analysis of complex cancer genomics and clinical profiles using the cBioPortal. Sci. Signal. 2013, 6. [CrossRef] [PubMed] 
34. Xie, S.; Xu, H.; Shan, X.; Liu, B.; Wang, K.; Cai, Z. Clinicopathological and prognostic significance of survivin expression in patients with oral squamous cell carcinoma: Evidence from a meta-analysis. PLoS ONE 2015, 10, e0116517. [CrossRef] [PubMed]

35. Sgaramella, N.; Coates, P.J.; Strindlund, K.; Loljung, L.; Colella, G.; Laurell, G.; Rossiello, R.; Muzio, L.L.; Loizou, C.; Tartaro, G.; et al. Expression of p16 in squamous cell carcinoma of the mobile tongue is independent of HPV infection despite presence of the HPV-receptor syndecan-1. Br. J. Cancer 2015, 113, 321-326. [CrossRef] [PubMed]

36. Polz-Gruszka, D.; Morshed, K.; Stec, A.; Polz-Dacewicz, M. Prevalence of Human papillomavirus (HPV) and Epstein-Barr virus (EBV) in oral and oropharyngeal squamous cell carcinoma in south-eastern Poland. Infect. Agent Cancer 2015, 10, 37. [CrossRef] [PubMed]

37. Melchers, L.J.; Mastik, M.F.; Samaniego Cameron, B.; van Dijk, B.A.; de Bock, G.H.; van der Laan, B.F.; van der Vegt, B.; Speel, E.J.; Roodenburg, J.L.; Witjes, M.J.; et al. Detection of HPV-associated oropharyngeal tumours in a 16-year cohort: More than meets the eye. Br. J. Cancer 2015, 112, 1349-1357. [CrossRef] [PubMed]

38. Belobrov, S.; Cornall, A.M.; Young, R.J.; Koo, K.; Angel, C.; Wiesenfeld, D.; Rischin, D.; Garland, S.M.; McCullough, M. The role of human papillomavirus in p16-positive oral cancers. J. Oral Pathol. Med. 2018, 47, 18-24. [CrossRef] [PubMed]

39. Lodi, G.; Franchini, R.; Bez, C.; Sardella, A.; Moneghini, L.; Pellegrini, C.; Bosari, S.; Manfredi, M.; Vescovi, P.; Carrassi, A. Detection of survivin mRNA in healthy oral mucosa, oral leucoplakia and oral cancer. Oral Dis. 2010, 16, 61-67. [CrossRef] [PubMed]

40. Kim, M.J.; Lim, K.Y.; Kim, J.W.; Nam, I.W.; Lee, J.H.; Myoung, H. Stage and mRNA expression of survivin in lymph node as prognostic indicators in patients with oral squamous cell carcinoma. Cancer Lett. 2005, 224, 253-261. [CrossRef] [PubMed]

41. Tanaka, C.; Uzawa, K.; Shibahara, T.; Yokoe, H.; Noma, H.; Tanzawa, H. Expression of an inhibitor of apoptosis, survivin, in oral carcinogenesis. J. Dent. Res. 2003, 82, 607-611. [CrossRef] [PubMed]

42. Liu, S.; Shi, L.; Yang, X.; Ye, D.; Wang, T.; Dong, C.; Guo, W.; Liao, Y.; Song, H.; Xu, D.; et al. Nuclear survivin promoted by acetylation is associated with the aggressive phenotype of oral squamous cell carcinoma. Cell Cycle 2017, 16, 894-902. [CrossRef] [PubMed]

43. Santarelli, A.; Mascitti, M.; Rubini, C.; Bambini, F.; Giannatempo, G.; lo Russo, L.; Sartini, D.; Emanuelli, M.; Procaccini, M.; Lo Muzio, L. Nuclear Survivin as a Prognostic Factor in Squamous-Cell Carcinoma of the Oral Cavity. Appl. Immunohistochem. Mol. Morphol. 2017, 25, 566-570. [CrossRef] [PubMed]

44. Lin, C.Y.; Hung, H.C.; Kuo, R.C.; Chiang, C.P.; Kuo, M.Y. Survivin expression predicts poorer prognosis in patients with areca quid chewing-related oral squamous cell carcinoma in Taiwan. Oral Oncol. 2005, 41, 645-654. [CrossRef] [PubMed]

45. Farnebo, L.; Tiefenbock, K.; Ansell, A.; Thunell, L.K.; Garvin, S.; Roberg, K. Strong expression of survivin is associated with positive response to radiotherapy and improved overall survival in head and neck squamous cell carcinoma patients. Int. J. Cancer 2013, 133, 1994-2003. [CrossRef] [PubMed]

46. Lo Muzio, L.; Farina, A.; Rubini, C.; Pezzetti, F.; Stabellini, G.; Laino, G.; Santarelli, A.; Pannone, G.; Bufo, P.; de Lillo, A.; et al. Survivin as prognostic factor in squamous cell carcinoma of the oral cavity. Cancer Lett. 2005, 225, 27-33. [CrossRef] [PubMed]

47. Engels, K.; Knauer, S.K.; Metzler, D.; Simf, C.; Struschka, O.; Bier, C.; Mann, W.; Kovacs, A.F.; Stauber, R.H. Dynamic intracellular survivin in oral squamous cell carcinoma: Underlying molecular mechanism and potential as an early prognostic marker. J. Pathol. 2007, 211, 532-540. [CrossRef] [PubMed]

48. Freier, K.; Pungs, S.; Sticht, C.; Flechtenmacher, C.; Lichter, P.; Joos, S.; Hofele, C. High survivin expression is associated with favorable outcome in advanced primary oral squamous cell carcinoma after radiation therapy. Int. J. Cancer 2007, 120, 942-946. [CrossRef] [PubMed]

49. Jane, C.; Nerurkar, A.V.; Shirsat, N.V.; Deshpande, R.B.; Amrapurkar, A.D.; Karjodkar, F.R. Increased survivin expression in high-grade oral squamous cell carcinoma: A study in Indian tobacco chewers. J. Oral Pathol. Med. 2006, 35, 595-601. [CrossRef] [PubMed]

50. Zhang, M.; Li, J.; Wang, L.; Tian, Z.; Zhang, P.; Xu, Q.; Zhang, C.; Wei, F.; Chen, W. Prognostic significance of p21, p27 and survivin protein expression in patients with oral squamous cell carcinoma. Oncol. Lett. 2013, 6, 381-386. [CrossRef] [PubMed] 
51. Bhosale, P.G.; Cristea, S.; Ambatipudi, S.; Desai, R.S.; Kumar, R.; Patil, A.; Kane, S.; Borges, A.M.; Schaffer, A.A.; Beerenwinkel, N.; et al. Chromosomal Alterations and Gene Expression Changes Associated with the Progression of Leukoplakia to Advanced Gingivobuccal Cancer. Transl. Oncol. 2017, 10, 396-409. [CrossRef] [PubMed]

52. Sticht, C.; Freier, K.; Knopfle, K.; Flechtenmacher, C.; Pungs, S.; Hofele, C.; Hahn, M.; Joos, S.; Lichter, P. Activation of MAP kinase signaling through ERK5 but not ERK1 expression is associated with lymph node metastases in oral squamous cell carcinoma (OSCC). Neoplasia 2008, 10, 462-470. [CrossRef] [PubMed]

53. Cumbo, F.; Fiscon, G.; Ceri, S.; Masseroli, M.; Weitschek, E. TCGA2BED: Extracting, extending, integrating, and querying The Cancer Genome Atlas. BMC Bioinf. 2017, 18, 6. [CrossRef] [PubMed]

54. Aquino, G.; Pannone, G.; Santoro, A.; Liguori, G.; Franco, R.; Serpico, R.; Florio, G.; de Rosa, A.; Mattoni, M.; Cozza, V.; et al. pEGFR-Tyr 845 expression as prognostic factors in oral squamous cell carcinoma: A tissue-microarray study with clinic-pathological correlations. Cancer Biol. Ther. 2012, 13, 967-977. [CrossRef] [PubMed]

(C) 2018 by the authors. Licensee MDPI, Basel, Switzerland. This article is an open access article distributed under the terms and conditions of the Creative Commons Attribution (CC BY) license (http://creativecommons.org/licenses/by/4.0/). 